\title{
Renal Dysfunction among HIV-infected Patients on Tenofovir-Based Antiretroviral Therapy at Ronald Ross Hospital in Zambia
}

\author{
Wantakisha $E^{1 *}$, Chongwe $\mathbf{G}^{2}$, Munkombwe $\mathrm{D}^{2}$ and Michelo $\mathrm{C}^{2}$
}

${ }^{1}$ Ronald Ross General Hospital, Ministry of Health, Mufulira, Zambia

${ }^{2}$ Department of Epidemiology, School of Public Health, University of Zambia, Lusaka, Zambia

\begin{abstract}
Objective: Tenofovir Disoproxil Fumerate (TDF) is contraindicated for use in HIV infected patients when creatinine clearance $(\mathrm{CrCl})$ is below $50 \mathrm{ml} / \mathrm{min}$. We determined prevalence and factors associated with renal dysfunction at 18 months follow up in adult HIV positive patients on TDF-based antiretroviral therapy (ART).
\end{abstract}

Methods: We conducted a cross sectional study of 445 HIV positive patients' records on a TDF-regimen at Ronald Ross General Hospital in Zambia. Patient's records in data management software (SMARTCARE) from 2008 to 2014 were reviewed to determine proportions of patients on TDF developing renal dysfunction. We estimated glomerular filtration rate (GFR) by creatinine clearance using the Cockcroft-Gault formula to determine renal dysfunction. $\mathrm{CrCl}$ level $\leq 50 \mathrm{ml} / \mathrm{min}$ indicated renal dysfunction. Multiple logistic regression was used to determine factors associated with renal dysfunction.

Results: At baseline ( $\mathrm{n}=429)$, median age of patients was 35 years (IQR 30,42), median $\mathrm{CrCl}$ level $106.2 \mathrm{ml} /$ min (IQR: 79.9, 127.8). At 18 months, median $\mathrm{CrCl} 102 \mathrm{ml} / \mathrm{min}$ (IQR: 81.6, 123.2) which remained within normal physiological range (88-137 $\mathrm{ml} / \mathrm{min})$. Point prevalence of renal dysfunction was $18.6 \%(95 \% \mathrm{Cl} ; 0.2-28.3)$. Multivariable analysis showed that ages $<50$ years than older (AOR: $0.0695 \% \mathrm{Cl} 0.01-0.27 ; \mathrm{p}<0.0001$ ), and those with higher CD4+ cell count $\geq 350$ cells/uL than lower (AOR: $0.1995 \% \mathrm{Cl} 0.03-0.21 ; \mathrm{P}=0.014$ ) had lower likelihood of renal dysfunction.

Conclusion: We found a high prevalence of renal dysfunction among HIV positive adults on tenofovir-based therapy. This was concentrated in older patients with low CD4+ cell counts suggesting a need for close renal function monitoring in this population when initiating tenofovir-based treatment.

Keywords: Tenofovir; Creatinine clearance; Antiretroviral therapy; Renal dysfunction; Prevalence

\section{Introduction}

Despite the fact that drug tolerability has improved and current available regimens have a reduced pill burden, toxicity remains the major cause of drug discontinuation [1]. The objective would be to strategically detect toxicity, virological failure early, which leads to adherence interventions or changes in therapy. The World Health Organization (WHO) revised the treatment guidelines for antiretroviral therapy (ART) in 2009 with recommendation for replacement of stavudine with either tenofovir or zidovudine $[2,3]$. State provision of ART in Zambia began late 2002. Ultimately, the state aspires to provide universal treatment access, so that ART therapy is equally available to everyone who is eligible. The toxicity problems of Zidovudine and Stavudine as well as the problematic resistance associated with failure of therapy, the preferred backbone used today of Tenofovir Disoproxil Fumerate (TDF)-based gives more treatment options in case of resistance.

Zambia adopted the use of TDF-based regimen in a first line drug choice for all newly eligible Human Immunodeficiency Virus (HIV) positive patients in 2007 [3]. TDF is an oral prodrug of tenofovir, a nucleotide reverse transcriptase inhibitor (NRTIs) that has been indicated for use from many randomized trials $[1,4-6]$ because of its favorable pharmacokinetic profile, availability as a once-daily fixed dose, good antiviral potency and high tolerability [3,7]. TDF has been considered safe and associated with fewer side-effects in many clinical trials $[4,5,8]$. However, there have been many case reports, cross sectional and cohort studies describing TDF associated and non-TDF associated nephrotoxicity [9-12]. However, there is increasing evidence suggesting that TDF has been associated with renal abnormalities [13] and more specifically that it can cause mild to moderate renal dysfunction $[10,12$ 15]. Early stages of renal dysfunction is assessed through laboratory monitoring of creatinine and glomerular filtration rate (GFR) calculated by the Cockcroft Gault formula or the Modification of Diet in Renal Disease (MDRD) $[14,16,17]$. In many studies recommendations and guidelines have been made, protocols developed that monitoring of renal function should be done by use of creatinine clearance on patients especially those exposed to TDF in intervals. In this study, interest was to determine prevalence of renal dysfunction and the associated factors in patients exposed to TDF-based antiretroviral therapy.

National guidelines recommends prescribing TDF as part of a first line drug combination to all newly eligible adults with normal renal function, defined as a $\mathrm{CrCl}>50 \mathrm{ml} / \mathrm{min}$. In Zambia, national guidelines recommends close renal monitoring at 2 weeks, 3 months and thereafter 6 monthly review of renal function for patients on ART. Mulenga and co-workers, recommends that if TDF is used as part of first line regimen, as is the case in Zambia, benefits should be weighed against

*Corresponding author: Enock Wantakisha, Department of Pathology and Microbiology, Ronald Ross General Hospital, PB 40987 Mufulira, Zambia, Tel: 0212411722, 0212411722; Fax: 410166; E-mail: wantakishaenock@yahoo.com

Received December 16, 2016; Accepted January 02, 2017; Published January 09, 2017

Citation: Wantakisha E, Chongwe G, Munkombwe D, Michelo C (2017) Renal Dysfunction among HIV-infected Patients on Tenofovir-Based Antiretroviral Therap at Ronald Ross Hospital in Zambia. J AIDS Clin Res 8: 651, doi: 10.4172/2155 6113.1000651

Copyright: (C) 2017 Wantakisha E, et al. This is an open-access article distributed under the terms of the Creative Commons Attribution License, which permits unrestricted use, distribution, and reproduction in any medium, provided the original author and source are credited. 
the more intensive renal monitoring that has to follow [9]. We argue that although TDF-based regimes are used, there is limited information on the proportion of patients that develop renal dysfunction. Further knowledge on the factors that may be associated with this development is also limited. In this paper, we aimed to determine the prevalence of renal dysfunction at 18 months follow up and the associated factors among HIV infected patients enrolled in an ART programme.

\section{Methods}

\section{Study setting and population}

Ronald Ross General Hospital is a level 2 hospital in Mufulira district of Zambia. It is a teaching hospital for nurses, pharmacy interns and is a main referral for over 18 clinics and one district hospital. The Counselling and Testing Center (CTC) at Ronald Ross General Hospital serves various members of the community in the district. The center has over 8,000 patients on ART. Patients receive multidisciplinary health care, including counselling, adherence meetings, follow-ups and reviews. The HIV/ART programme has been going on at the hospital since 2001.

\section{Study design}

Smart care database: The ART patient's demography, laboratory profile, pharmacy management, or follow up data and other patient parameters such as review dates are entered in the data management software called SMARTCARE. Data at every patient review is entered into this software. We extracted data from this software and confirmed the data with the patient files for validation.

Renal dysfunction design: A minimum sample of $344 \mathrm{HIV}$ positive patients was calculated at $90 \%$ statistical power to be the study size. Adjusting for loss to follow up at $80 \%, 430$ patients were considered. The selection criteria for eligibility were availability of creatinine results at baseline, patients on TDF-based regimen with no confirmed renal abnormalities. Based on this criterion, 429 records with relevant information were reviewed and the data were validated with the patient files.

We focused on records of patients aged 15 years and above who were enrolled at CTC from February 11, 2008 through to September 15,2014 . The records were examined for completeness after being reviewed by a team composed of a biomedical scientist, pharmacist, health management information officer, medical doctor, and a nursing sister. Records that had baseline CD4+ cell count, weight, blood creatinine were selected into the study. Records of patients without conditions, which increase blood creatinine levels such as (Known renal dysfunction before HIV diagnosis, chronic nephritis, urinary tract obstruction, HIV-associated nephropathy, and congestive heart disease) were included in the study [18]. Records were excluded if they had no follow up laboratory results.

\section{Data extraction}

From the records that met the eligibility criteria, 429 records were extracted from SMARTCARE database for this study. This therefore composed the total sample conducted as part of the cross sectional study of HIV positive patients' records on ART regimen defined according to the Ministry of Health consolidated antiretroviral therapy Standard Operating Procedure (SOP) for adults and adolescents [3]. After extraction, data were then re-entered into Excel database and thereafter exported into Stata (College Station, TX; version 12) for analysis. CD4+ cell count changes, creatinine levels and changes in weight at baseline and 18 months were also extracted and entered. Other patient demographic and medical characteristic such as education level, employment status, and use of concomitant medication such as, cotrimoxazole, and anti-mycobacterium tuberculosis medication were also extracted and entered.

\section{Measurements}

Measurements were carried out to determine values at baseline defined as $\leq 60$ days of regimen before initiation and at 18 months after initiation of therapy. This included; CD4+ cell count (cells/ $\mathrm{uL})$, creatinine $(\mu \mathrm{mol} / \mathrm{L})$, urea $(\mathrm{mmol} / \mathrm{L})$ and weight $(\mathrm{kg})$. Creatinine clearance was calculated using the Cockcroft-Gault formula with weight taken on the same day that creatinine measurements were performed. The Chronic Kidney Disease-Epidemiology Collaboration (CKD-EPI) equation is accurate than the other two-GFR-estimating equation [19] in common use. Rule et al. adds that the conclusion is based on equation performance in arbitrary combination of low-risk and highrisk patients. The Cockcroft-Gault formula was preferred because it is relatively easy to use compared to the MDRD. MDRD has not been validated in acute renal failure and since the formula does not adjust for body mass relative to the Cockcroft-Gault formula it underestimates GFR for weighted people and overestimates it for underweight people $[8,15,20]$.

$$
\text { Estimated } \mathrm{CrCl}(\mathrm{mL} / \mathrm{min})=\frac{(140 \text {-age }[\text { years }] \times \text { weight }[\mathrm{kg}])}{(0.815 \times \mathrm{SCr}(\mu \mathrm{mol} / \mathrm{L}))}
$$

Multiplied by 0.85 for females .

Creatinine clearance was calculated at two time points before initiation and at 18 months of ART. Renal dysfunction at each time point was also classified into stages according to the Kidney Disease Outcomes Quality Initiative Classification (K/DOQI) criterion by GFR. The K/DOQI categorizes renal dysfunction as follows; $\mathrm{CrCl} \geq 90 \mathrm{ml} / \mathrm{min}$ considered no renal dysfunction; $\mathrm{CrCl}$ of $60-89 \mathrm{ml} / \mathrm{min}$ as mild renal dysfunction (Stage 2); $\mathrm{CrCl}$ of $30-59 \mathrm{ml} / \mathrm{min}$ as moderate dysfunction (Stage 3); and $\mathrm{CrCl}$ lower than $30 \mathrm{ml} / \mathrm{min}$ as severe dysfunction (Stages 4 and 5). Renal dysfunction at 18 months was further categorized into $\mathrm{CrCl} \leq 50 \mathrm{ml} / \mathrm{min}$ and $>50 \mathrm{ml} / \mathrm{min}$ because current guidelines contraindicate use of TDF when $\mathrm{CrCl}$ falls below $50 \mathrm{ml} / \mathrm{min}$.

\section{Statistical analysis}

All continuous variables were assessed for skewness. Variables with non-Gaussian distribution were compared using Wilcoxon signed-rank test and described by reporting their median and interquartile ranges. For categorical variables, proportions or percentages were reported and chi-square test used to assess associations between variables. Multivariable logistic regression analysis was performed to determine factors that are associated with renal dysfunction. All reported values are exact and two-tailed, $\mathrm{p}$-value of $<0.05$ was considered significant. We measured changes in creatinine, $\mathrm{CrCl}, \mathrm{CD} 4+$ cell count, urea and weight.

\section{Ethical approval}

The study was approved by The University of Zambia Biomedical Research Ethics committee (REF.No.003-07-15). The use of reference numbers (codes) provided the privacy, confidentiality of patient's files and ensured the integrity of the data. Access to the data files and data extraction tools was highly restricted and codes have not been used in reporting. This did not infringe on participants' privacy and was judged by ourselves to pose minimal to no risk. In addition to the above ethical measures, we also obtained permission from Ronald Ross General Hospital management to conduct the study. 
Citation: Wantakisha E, Chongwe G, Munkombwe D, Michelo C (2017) Renal Dysfunction among HIV-infected Patients on Tenofovir-Based Antiretroviral Therapy at Ronald Ross Hospital in Zambia. J AIDS Clin Res 8: 651. doi: 10.4172/2155-6113.1000651

Page 3 of 6

\section{Results}

\section{Baseline characteristics}

At baseline (n=429), median age was 35 years (IQR: 30, 42), median weight was $55 \mathrm{~kg}$ (IQR: $49.5,61$ ), CD4+ cell count was 213.5 cells $/ \mathrm{uL}$ (IQR: 114, 339.5) and median baseline $\mathrm{CrCl}$ level was $10^{6} \mathrm{ml} / \mathrm{min}$ (IQR: $79.9,127.8)$. Most of the patients were females aged $<50$ years old, employed and had a secondary level education (Table 1). Baseline blood creatinine was within normal physiological functions for 241 adults and adolescents prior to initiating ART. On initiation, 429 patients were started on TDF correctly according to ART standard guidelines. Only blood creatinine, weight and CD4+ cell count were statistically significantly different at 18 months of TDF-based therapy (Table 2).

\section{Renal dysfunction and associated factors}

Point prevalence of renal dysfunction among HIV-positive adults exposed to TDF was $18.6 \%$ at 18 months follow up. Categorized by age, sex and other variables as depicted in Table 3 , those who had a CD4+ cell count $<350$ cells/uL, age $>50$ and high blood creatinine accounted for the highest prevalence relative to renal dysfunction case proportions. On multiple logistic regression analysis, Patients with a CD4+ cell count $>350$ cells/uL had decreased odds of developing renal dysfunction by $81 \%$ and this decrease could be as low as $79 \%$ to as high as $97 \%$ adjusting for other covariates as depicted in Table 3 with $95 \%$ CI. Those with higher CD4+ cell count $>350$ cells/uL had less likelihood of renal dysfunction.

\begin{tabular}{|c|c|c|}
\hline Characteristics & n (\%) & Median (IQR) \\
\hline \multicolumn{3}{|l|}{ Sex } \\
\hline Male & $129(30.07)$ & - \\
\hline Female & $300(69.93)$ & - \\
\hline \multicolumn{3}{|l|}{ Age (years) } \\
\hline $15-34$ & $203(47.32)$ & $29(27,32)$ \\
\hline $35-49$ & $188(43.82)$ & $40(37,43)$ \\
\hline $50-80$ & $38(8.86)$ & $56(53,61)$ \\
\hline \multicolumn{3}{|l|}{ Education } \\
\hline Primary & $124(34.44)$ & - \\
\hline Secondary & $171(47.50)$ & - \\
\hline Tertiary & $65(18.06)$ & - \\
\hline \multicolumn{3}{|l|}{ Employment Status } \\
\hline Employed & $198(59.82)$ & - \\
\hline Not employed & $133(40.18)$ & - \\
\hline \multicolumn{3}{|l|}{ Blood Creatinine ( $\mu \mathrm{mol} / \mathrm{L})$} \\
\hline Low & $192(44.76)$ & $50(41,53)$ \\
\hline High & $237(55.24)$ & $70.5(63,80)$ \\
\hline \multicolumn{3}{|l|}{ CD4+ Cell count (count/uL) } \\
\hline$<350$ & $334(77.86)$ & $170(85,240)$ \\
\hline$>350$ & $95(22.14)$ & $435(386,533)$ \\
\hline \multicolumn{3}{|c|}{ Creatinine Clearance (ml/min) } \\
\hline$<50$ & 0 & \\
\hline$\geq 50$ & $429(100)$ & $106(79.9,127.7)$ \\
\hline \multicolumn{3}{|c|}{ Antiretroviral Drug Combinations } \\
\hline TDF/FTC/EFV & $102(23.15)$ & - \\
\hline TDF/FTC/NVP & $327(76.85)$ & - \\
\hline TDF/FTC/LPV/r & 0 & - \\
\hline
\end{tabular}

Note: 1) The total sample size, $n=429.2$ ) Descriptive statistics described using median and interquartile range (IQR) 3) TDF: Tenofovir; FTC: Emtricitabine; EFV: Efavirenz; NVP: Nevirapine

Table 1: Baseline characteristics of HIV patients on a Tenofovir-based ART therapy at Ronald Ross Hospital in Zambia.
In addition, patients older than 50 years were 0.06 times more likely to develop renal dysfunction adjusting for sex. CD4+ cell count, weight, exposure to Tubercle bacilli (TB) medication and blood creatinine [AOR; 0.06 95\% CI: (0.01, 0.27); $\mathrm{p}<0.001]$. Males were 1.61 times

\begin{tabular}{|c|c|c|c|}
\hline Characteristics & Baseline & 18 months & P-value \\
\hline & Median (IQR) & Median (IQR) & \\
\hline \multicolumn{4}{|l|}{ Blood Creatinine $(\mu \mathrm{mol} / \mathrm{L})^{a}$} \\
\hline Low & $50(41,53)$ & $51(42,55)$ & 0.02 \\
\hline High & $70.5(63,80)$ & $73(67,84)$ & \\
\hline \multicolumn{4}{|l|}{ CD4+ Cell count (count/uL) } \\
\hline$<350$ & $170(85,240)$ & $252(186,294)$ & $<0.001$ \\
\hline$>350$ & $435(383,533)$ & $512.8(413,626)$ & \\
\hline \multicolumn{4}{|l|}{ Creatinine Clearance $(\mathrm{ml} / \mathrm{min})^{\mathrm{a}}$} \\
\hline$<50$ & 0 & $43(39.5,47.6)$ & 0.86 \\
\hline$\geq 50$ & $106(79.9,127)$ & $104(85,124.1)$ & \\
\hline \multicolumn{4}{|l|}{ Weight $(\mathbf{k g})^{b}$} \\
\hline$<55$ & $49(4.85)$ & $50.75(4.32)$ & $<0.001$ \\
\hline$>55$ & $61(6.18)$ & $62(6.92)$ & \\
\hline \multicolumn{4}{|l|}{ Renal dysfunction } \\
\hline Normal GFR & $118(106,137)$ & $117(104,136)$ & 0.98 \\
\hline Slightly decease GFR & $73.1(67.2,77)$ & $71.4(67,75.65)$ & \\
\hline Moderate decrease GFR & $55(53.55,57.8)$ & $49.3(44,55.3)$ & \\
\hline Severe decrease GFR & 0 & $28.9(29.9,28.9)$ & \\
\hline Kidney failure & 0 & 0 & \\
\hline
\end{tabular}

Note: 1) Sample size, $n=429$ 2) ${ }^{a}$ Median (IQR), Wilcoxon signed-rank test 3$)^{b}$ Mean (SD), Two-sample test of proportions and Chi-square test (Categorical variables)

Table 2: Clinical characteristics of HIV patients at baseline and 18 months follow up on a Tenofovir-based ART therapy at Ronald Ross Hospital in Zambia.

\begin{tabular}{|c|c|c|c|c|}
\hline Characteristics & $\begin{array}{l}\text { Proportion } \\
\text { renal }\end{array}$ & $\begin{array}{c}\text { Prevalence } \\
(\%)\end{array}$ & Adjusted Odds & P-value \\
\hline & $\begin{array}{l}\text { dysfunction } \\
\text { (n) }\end{array}$ & & Ratio $(95 \% \mathrm{Cl})$ & \\
\hline \multicolumn{5}{|l|}{ Sex } \\
\hline Female & $9(300)$ & 3 & Ref & Ref \\
\hline Male & $2(129)$ & 1.6 & $1.60(0.29-8.89)$ & 0.590 \\
\hline \multicolumn{5}{|l|}{ Age(years) } \\
\hline$<50$ & $3(393)$ & 0.8 & Ref & Ref \\
\hline$>50$ & $8(52)$ & 15.4 & $0.06(0.01-0.27)$ & $<0.0001$ \\
\hline \multicolumn{5}{|l|}{ CD4+ cell count } \\
\hline$<350$ & $5(155)$ & 3.2 & Ref & Ref \\
\hline$>350$ & $5(72)$ & 6.9 & $0.19(0.03-0.21)$ & 0.014 \\
\hline \multicolumn{5}{|l|}{ Baseline weight } \\
\hline$<55$ & $8(220)$ & 3.6 & Ref & Ref \\
\hline$>55$ & $3(225)$ & 1.3 & $4.04(0.77-21.30)$ & 0.125 \\
\hline \multicolumn{5}{|l|}{ TB medication } \\
\hline No & $5(245)$ & 2.0 & Ref & Ref \\
\hline Yes & $4(150)$ & 2.7 & $0.38(0.07-1.96)$ & 0.247 \\
\hline \multicolumn{5}{|l|}{ Blood creatinine } \\
\hline Low & $3(192)$ & 1.6 & Ref & Ref \\
\hline High & $8(237)$ & 3.4 & $0.33(0.06-1.92)$ & 0.217 \\
\hline
\end{tabular}

Note: 1) Overall renal dysfunction prevalence at 18 months follow up was $18.6 \%$ $(n=429) 2$ ) Sample values exclude 16 patients who had renal dysfunction before TDF initiation (Baseline). 3) The multivariable logistic regression model adjusted for all other variables. 4) Bold text indicates the $p$ values that were $<0.05$.Predictor variables included in full model: Age and CD4+ cell count. aOR: Adjusted Odds Ratio; Cl:Confidence interval

Table 3: Determinants of renal dysfunction of HIV patients at 18 months follow up on tenofovir-based therapy by categories at Ronald Ross Hospital Zambia. 


\begin{tabular}{|c|c|c|c|c|}
\hline & $\begin{array}{c}\text { CD4+cell } \\
\text { difference }\end{array}$ & $\begin{array}{c}\text { Prevalence } \\
\%(\mathbf{n})\end{array}$ & aOR (95\% Cl) & p-value \\
\hline Group with young & $\leq 350$ & $0.56(177)$ & Ref & \\
\cline { 2 - 5 } & patients & $4.87(41)$ & $0.24(0.06-0.79)$ & 0.011 \\
\hline \multirow{2}{*}{$\begin{array}{c}\text { Group with older } \\
\text { patients }\end{array}$} & $\leq 350$ & $2.34(171)$ & Ref & \\
\cline { 2 - 5 } & $>350$ & $7.69(56)$ & $4.25(1.26-14.33)$ & 0.019 \\
\hline
\end{tabular}

Notes: 1) Sample size $\mathrm{n}=429$. 2) Those with $\mathrm{CrCl}<50 \mathrm{ml} / \mathrm{min}$ at start of treatment were excluded 3) age defined: younger $<50$ years and older $>50$ years 4 ) aOR:Adjusted Odds Ratios

Table 4: CD4+ cell count difference of renal dysfunction in HIV patients on TDF at 18 months follow up by age categories at Ronald Ross Hospital Zambia.

more likely to develop renal dysfunction than females though this was not statically significant. At 18 months of follow up however, females had more renal dysfunction cases than males (ratio; 4:1). Weight was not associated with abnormal renal function [AOR: $4.0495 \% \mathrm{CI}$ : $(0.77,21.30)$; $\mathrm{p}$-value $=0.125]$, further having a physiologically normal baseline urea and creatinine level was less likely associated with renal dysfunction. Patients who were old than 50 years and had a CD4+ cell count $<350$ had more likelihood of renal dysfunction than those below 50 years (Table 4 ). There was a high prevalence of renal dysfunction noticed in older patient above 50 years adjusting for CD4+ cell count.

In multivariable analysis, patients who had a baseline CD4+ cell count $>350$ cells/uL than $<350$ cells/uL (AOR: 0.19 (0.03-0.21), $\mathrm{P}=0.014)$ controlling for age, sex, weight, exposure to $\mathrm{TB}$ medication and creatinine were less likely to develop renal dysfunction (Table 3). Use of cotrimoxazole, TB medication and urea levels at the time of ART initiation were not likely to lead to abnormal renal function at 18 months follow up. The median CD4+ cell count increased from baseline CD4+ cell count 213.5/uL (IQR: $114,339.5$ ) to 390 cells/uL (IQR: 274, 543) at 18 months. Females were 1.61 less likely than men to have reduced $\mathrm{CrCl}<50 \mathrm{ml} / \mathrm{min}$ (renal dysfunction) though this was not statistically significant ( $95 \%$ CI $0.29-8.89, \mathrm{P}=0.590)$. Of the total patients reviewed, 429 presented with a baseline $\mathrm{CrCl}>50 \mathrm{ml} / \mathrm{min}$.

\section{Creatinine clearance and renal dysfunction}

A total of 429 adults and adolescents with a baseline $\mathrm{CrCl} \geq 50 \mathrm{ml} /$ min were correctly started on TDF. Creatinine clearance was calculated in $429(100 \%)$ patients at baseline, $415(97 \%)$ at 6 months, $325(78 \%)$ at 12 months and 294 (69\%) at 18 months. Our interest was to compare two time points; baseline and 18 months creatinine clearance. Creatinine clearance was not performed in more than one third of measurement at 18 months. Among those who presented with $\mathrm{CrCl}>50 \mathrm{ml} / \mathrm{min}$ two actually fulfilled the criteria for Fanconi syndrome.

\section{Discussion}

ART regimens adverse effects remain a challenge facing the public health sector that require safe-regular monitoring to prolong life. We set out to estimate the prevalence and associated risk factors of renal dysfunction among HIV positive adults exposed to TDF in an active antiretroviral therapy programme. The results of this study have shown a point prevalence of renal dysfunction among HIV-positive adults exposed to TDF as $18.6 \%$ at 18 months follow up. It has further shown that old age and low CD4+ cell count were important risk factors for development of renal dysfunction in this population. These findings showed that those patients who had CD4+ cell counts $>350$ cells/uL and a baseline creatinine within the normal physiological levels were less likely to develop renal dysfunction. The higher the age, the more likely they were to develop renal dysfunction. Considering that most patients in Zambia begin on a TDF combined therapy, and that this is life-long treatment, screening at every follow up visit should be intensified.

The prevalence found in this study agrees to similar studies done around the world ranging from $3.6 \%$ to $42 \%$ [9,12,21,22]. The risk factors for renal dysfunction that we found in this population are consistent with previous findings, for example, in the adult population at University Teaching Hospital, Zambia $[9,10]$ which suggested that $\mathrm{CD} 4+$ cell counts is an important risk factor. Other studies have suggested an association between CD4+ cell count of less than 200 cells/uL and renal dysfunction among patients exposed to TDF $[6,9,23]$. In this study, the median CD4+ cell count was 243.9 cells/ $\mathrm{uL}$ for those with $\mathrm{CrCl}>50 \mathrm{ml} / \mathrm{uL}$ eliminating the assumption that renal dysfunction in this group could have been due to advanced HIV infection. Conversely, patients with median CD4+ cell count $<350$ cells/uL at baseline developed renal dysfunction consistent with other studies done in other countries [13,23,24]. The mechanism underlying renal toxicities are not fully understood.

The high prevalence of renal dysfunction evidenced in this population can be explained by the long duration of the disease among the population. In fact, it is possible that the prevalence will be an underestimate. This is because there were 16 patients who had $\mathrm{CrCl} \leq 50 \mathrm{ml} /$ min at baseline but were initiated on TDF (in error) suggesting that screening at initiation is not intensified. This further suggests that there are cases of renal dysfunction in this population that are not noticed during patients' review visits. For instance, we found that over onethird of population had no creatinine clearance calculated according to recommended national guidelines.

Renal dysfunction deaths in Zambia stood at 16.37 per 100,000 in 2014 [25]. Despite being one of the countries affected with high HIV burden, there is limited data on renal disease and the risk factors predisposing the population to it. TDF currently is a recommended first-line agent in combination with other antiretroviral drugs for HIV management in Zambia. This is because of its favorable pharmacokinetic profile, good antiviral potency and high tolerability $[3,7]$. The high number of renal dysfunction cases missed at initiation and follow up suggests that screening of patients prior to initiation is rare. This emphasizes the importance of routine follow up of creatinine clearance prior to TDF initiation as recommended. Although discontinuation of TDF resulted in renal recovery in the majority of the cases, some patients however experienced chronic kidney disease up to the end of study. Among those who presented with $\mathrm{CrCl}>50 \mathrm{ml} / \mathrm{min}$ at baseline, two actually fulfilled the criteria for Fanconi syndrome. It is not surprising; however, that such small incremental decline in renal function could not be noticed considering that most clinicians do not follow GFR but rather blood creatinine and urea. The gradual increase in CD4+ cell count observed is reassuring because lower CD4+ cell count is independently associated with accelerated kidney dysfunction. In this study, creatinine clearance monitoring as recommended was not consistent. Implementation of TDF in health facilities in which lessertrained health cadres will be responsible for routine care provision will thus need to be accompanied by assessment of tools and protocols to ensure that $\mathrm{CrCl}$ is performed.

In the public health approach [24] to ART scale up that occurs in Zambia, screening for renal impairment prior to starting ART does not routinely take place as evidenced by high number of creatinine clearance performed. There are several reasons why screening for renal impairment may improve patient outcomes. First and foremost, clinicians can apply more intensive follow up procedures for such patients at higher risk of renal dysfunction and reduce mortality related to ART $[9,21]$. Monitoring of renal function includes estimating GFR and 
the detection of proteinuria at regular intervals. A tubular dysfunction is an early event that precedes the decline in glomerular filtration rate. With high mortality rates $(25 \%-80 \%)$ due to renal dysfunction more dependent on cause of kidney injury and co-morbidities [21], indicate why intensive renal monitoring is vital. Secondly, failure to change the ART regimen early on patients at risk of renal dysfunction can increase mortality. This can only be reduced if and when the GFR can routinely be monitored in this ART programme. Thirdly, patients with HIV and renal impairment may benefit from management of their renal problem. As evidenced in this study, quite a number of ineligible patients who should not begin on TDF-based therapy are missed at initiation.

Our limitations in this study had to do with how we defined renal dysfunction, which differed, in our analysis with other studies such as Freeman et al. and Szczech et al. We used estimated creatinine clearance as a categorical variable to define renal dysfunction and not serum creatinine as a continuous predictor variable. In addition, some of these studies that demonstrated low mild or severe renal dysfunction prevalence due to TDF, had more covariates (diabetes, Hepatitis co-infection and hypertension) than we did. Thus, these studies had the ability to control for a variety of covariates potentially associated with renal dysfunction. These covariates have been described in other studies to be risk factors accounting for $2-8 \%$ of renal dysfunction, as thus our prevalence maybe an overestimate. Furthermore, one cannot rule out the possibility of measurement bias in the way the study collected the results. The strength of our study lies in the fact that we used data from a routine ART programme setting in an established programme using SMART CARE and verified with patients files The data provided a useful comparison to data derived from more controlled and better resource research settings.

\section{Conclusion and Recommendation}

This study has shown differential effects of patients CD4+ cell count, age, and ART on the risk of renal dysfunction. We found a high burden of TDF-based antiretroviral therapy associated renal dysfunction among HIV-infected in our study population. Renal dysfunction was concentrated in older patients with low CD4+ cell count. Thus, close renal monitoring in these patients when initiating TDF-based treatment should be intensified.

Although efficacious, TDF exposure must always be accompanied by more intensive renal monitoring particularly in patients at higher risk of renal dysfunction. Long-term monitoring of renal function by creatinine clearance at appropriate intervals accompanied by measurement of creatinine is vital. Considering the high burden of HIV and the cost of laboratory monitoring in resource-limited sites, implementation of TDF-based therapy should balance the long term renal monitoring with cost effectiveness.

\section{Acknowledgement}

We thank Gallet Zulu, Mary Phiri, and James Malakata for the assistance with the data collection and review of patient's files and use of SMART CARE. We thank the Ministry of Health for supporting the research as the main sponsor. The sponsor had no role in the design or conduct of the study, in the collection, analysis, or interpretation of data, or in the preparation of the manuscript.

\section{References}

1. Della Negra M, De Carvalho AP, De Aquino MZ, Pinto JA, Da Silva MT, et al (2015) Long-term efficacy and safety of tenofovir disoproxil fumarate in HIV1 -infected adolescents failing antiretroviral therapy: The final results of study GS-US-104-0321. Pediatr Infect Dis J 34: 398-405

2. Anon (2009) Antiretroviral therapy for HIV infection in adults and adolescents World Health Organisation, Geneva.
3. Ministry of Health (2013) Antirereoviral therapy treatment standard operating procedure for adults and adolescents. Antirtroviral Therapy Guiderline, Ministry Of Health.

4. Swartz JE, Vandekerckhove L, Ammerlaan $\mathrm{H}$, de Vries AC, Begovac J, et al. (2015) Efficacy of tenofovir and efavirenz in combination with lamivudine or emtricitabine in antiretroviral-naive patients in Europe. J Antimicrob Chemother 70: $1850-1857$

5. Kabbara WK, Ramadan WH (2015) Emtricitabine/rilpivirine/tenofovir disoproxil fumarate for the treatment of HIV-1 infection in adults. J Infect Public Health 8: 409-417.

6. Bygrave H, Ford N, van Cutsem G, Hilderbrand K, Jouquet G, et al. (2011) Implementing a tenofovir-based first-line regimen in rural Lesotho: Clinical outcomes and toxicities after two years. J Acquir Immune Defic Syndr 56: e75-e78.

7. Patel KK, Patel AK, Ranjan RR, Patel AR, Patel JK (2010) Tenofovir-associated renal dysfunction in clinical practice: An observational cohort from western India. Indian J Sex Trans Dis 31: 30-34.

8. Sax PE, Wohl D, Yin MT, Post F, DeJesus E, et al. (2015) Tenofovir alafenamide versus tenofovir disoproxil fumarate, coformulated with elvitegravir, cobicistat, and emtricitabine, for initial treatment of HIV-1 infection: Two randomised, double-blind, phase 3, non-inferiority trials. Lancet 385: 2606-2615.

9. Mulenga LB, Kruse G, Lakhi S, Cantrell RA, Reid SE, et al. (2008) Baseline renal insufficiency and risk of death among HIV-infected adults on antiretroviral therapy in Lusaka, Zambia. AIDS 22: 1821-1827.

10. Freeman C, Gibson S, Aggrey M, Mwenya K, kasonde M, et al. (2015) Comparison of creatinine clearance in HIVIAIDS Patients on Tenofovir and two non-Tenofovir- based NRTIs after one year of therapy. J Med Sci Technol 4 : 97-103.

11. Wools-Kaloustian K, Gupta SK, Muloma E, Owino-Ong'or W, Sidle J, et al. (2007) Renal disease in an antiretroviral-naive HIV-infected outpatien population in Western Kenya. Nephrol Dial Transplant 22: 2208-2212.

12. Mitra S, Priscilla R, Rajeev K, Sauradeep S, Rajkumar S, et al. (2014) Renal tubular dysfunction associated with tenofovir therapy. J Assoc Physicians India 62: $580-582$

13. Pichit D, Somnue $S$ (2010) Use of tenofovir disoproxil fumarate and the monitoring of renal function among HIV-1 infected patients in a resource-limited setting. J Infect Dis Antimicrob Agents 27: 77-84.

14. Bygrave H, Kranzer K, Hilderbrand K, Jouquet G, Goemaere E, et al. (2011) Renal safety of a tenofovir-containing first line regimen: Experience from an antiretroviral cohort in rural Lesotho. PloS one 6: e17609.

15. Szczech LA (2008) Renal dysfunction and tenofovir toxicity in HIV-infected patients. Top HIV Med 16: 122-126.

16. Rokx C, Van der Ende ME, Rijnders BJ (2015) How does weight influence tenofovir disoproxil-fumarate induced renal function decline? Aids 29: 643-645

17. Giacomet V, Nannini P, Vigano A, Erba P, Benincaso A, et al. (2015) Longterm renal effects of Tenofovir-Disoproxil-Fumarate in vertically HIV-infected children, adolescents, and young adults: A 132-month follow-up study. Clin Drug Investig 35: 419-426.

18. Ganong W (2003) Review of medical physiolog (21st edn) McGraw-Hill Medical Publishing Division.

19. Rule AD (2010) The CKD-EPI equation for estimating GFR from serum creatinine: Real improvement or more of the same? Clin J Am Soc Nephrol 5: 951-953.

20. Thuppal SV, Wanke CA, Noubary F, Cohen JT, Mwamburi M, et al. (2015) Toxicity and clinical outcomes in patients with HIV on zidovudine and tenofovir based regimens: A retrospective cohort study. Trans R Soc Trop Med Hyg 109 379-385.

21. Banda J, Mweemba A, Siziya S, Mweene M, Andrews B, et al. (2010) Prevalence and factors associated with renal dysfunction in HIV positive and negative adults at the university teaching hospital, in Lusaka. Med J Zambia 37: $136-142$

22. Msango L, Downs JA, Kalluvya SE, Kidenya BR, Kabangila R, et al. (2011) Renal dysfunction among HIV-infected patients starting antiretroviral therapy. Aids 25: 1421-1425. 
Citation: Wantakisha E, Chongwe G, Munkombwe D, Michelo C (2017) Renal Dysfunction among HIV-infected Patients on Tenofovir-Based Antiretroviral Therapy at Ronald Ross Hospital in Zambia. J AIDS Clin Res 8: 651. doi: 10.4172/2155-6113.1000651

Page 6 of 6

23. Micheal H, Beth T, William T, Micheal S, Susan B, et al. (2009) Impact of tenofovir on renal function in HIV -infected, antiretroviral-naive patients. Acquir Immune Defic Syndr 53: 62-69.

24. Struik GM, den Exter RA, Munthali C, Chipeta D, van Oosterhout JJ, et al.
(2011) The prevalence of renal impairment among adults with early HIV disease in Blantyre, Malawi. Int J Std AIDS 22: 457-462.

25. WHO (2014) Kidney disease death rate per 100,000 age standardized. World Health Organization. 